\title{
Microstructure evolution and mechanical properties of Mg-12Zn-2Y alloy containing quasicrystal phase fabricated by different casting processes
}

\author{
Ji-guang Liu', Bu-ke Dong', *Xiao-gang Fang ${ }^{1,2}$, Bin Li', You-wen Yang', Tian-yu Wu', Rui-dong Ren', Shu-sen Wu² \\ 1. School of Materials Science and Engineering, Hefei University of Technology, Hefei 230009, China \\ 2. State Key Lab of Materials Processing and Die \& Mould Technology, Huazhong University of Science and Technology, Wuhan 430074, China
}

\begin{abstract}
Although icosahedral quasicrystal phase (denoted as I-phase) has been verified as an outstanding reinforcing phase, the mechanical properties of quasicrystal-reinforced $\mathrm{Mg}-\mathrm{Zn}-\mathrm{Y}$ alloys fabricated by traditional casting processes are still unsatisfactory due to the serious segregation of intermetallic compounds. In this study, the microstructure and mechanical properties of $\mathrm{Mg}-12 \mathrm{Zn}-2 \mathrm{Y}$ alloy fabricated by different casting processes, including permanent mold casting, squeeze casting and rheo-squeeze casting with ultrasonic vibration, were systematically investigated and compared. The results show that massive, large-sized I-phase and $\mathrm{Mg}_{7} \mathrm{Zn}_{3}$ phase gather together in the permanent mold cast sample, while the squeeze casting process leads to the transformation of I-phase into fine lamellar morphology and the amount of $\mathrm{Mg}_{7} \mathrm{Zn}_{3}$ decreases. As to the rheosqueeze casting process, when the ultrasonic vibration is exerted with power from $800 \mathrm{~W}$ to $1,600 \mathrm{~W}$, the $\alpha-\mathrm{Mg}$ grains are refined and spheroidized to a large extent, and the lamellar spacing of the eutectic structure is significantly reduced, accompanied by some tiny granular I-phase scattering in the a-Mg matrix. However, when the ultrasonic power continuously increases to $2,400 \mathrm{~W}$, the eutectic structure becomes coarse. The best mechanical properties of the rheo-squeeze cast alloy are obtained when the ultrasonic power is $1,600 \mathrm{~W}$. The microhardness, yield strength, ultimate tensile strength and elongation are $79.9 \mathrm{HV}, 140 \mathrm{MPa}, 236 \mathrm{MPa}$, and $3.25 \%$, which are $44.1 \%, 26.1 \%, 25.5 \%, 132.1 \%$ respectively higher than the corresponding values of the squeeze casting sample, and are $47.6 \%, 44.3 \%, 69.8 \%$, and $253.3 \%$ respectively higher than the corresponding values of the permanent mold casting sample.
\end{abstract}

Key words: Mg-Zn-Y alloy; quasicrystal; rheo-squeeze casting; ultrasonic vibration treatment

CLC numbers: TG146.22 Document code: A

Article ID: 1672-6421(2021)02-147-08

\section{Introduction}

Magnesium alloy has the characteristics of low density, high specific strength and large elastic modulus, and is widely used in electronic communication, transportation, aerospace, and other fields ${ }^{[1-3]}$. However, compared with other cast alloys, thermomechanical properties and heat resistance of conventional cast magnesium alloy are lower, which limit the industrial application of magnesium alloy ${ }^{[4,5]}$. Some researchers have studied the effect of the quasicrystal phase on the mechanical

\section{*Xiao-gang Fang}

Male, born in 1989, Ph. D. His research interests mainly focus on the development of new light alloy materials, liquid metal forming technology, and numerical simulation of the casting process. To date, he has published more than 20 technical papers.

E-mail: fangxg@hfut.edu.cn;

Received: 2020-10-09; Accepted: 2021-01-07 properties of alloys. In 1993, Luo et al. ${ }^{[6-9]}$ reported that the stable quasicrystal phase was found in as-cast $\mathrm{Mg}$ Zn-RE (Y, Gd, Nd, La, Ce, etc) alloys, which exhibited some excellent properties such as high hardness, low interface energy, outstanding corrosion resistance and high temperature stability. However, when Mg$\mathrm{Zn}-\mathrm{Y}$ alloy was melted in an electric furnace and slowly cooled in air, the quasicrystal phases existed in the form of icosahedron and bulky intermetallic compounds as well as aggregated at grain boundaries, which is harmful to the improvement of mechanical properties ${ }^{[6]}$. It was reported that the small-sized and uniformly-distributed quasicrystals could improve the properties of alloys significantly ${ }^{[10]}$. Zhang et al. ${ }^{[1]}$ reported that fine I-phase precipitates formed in the hot extrusion process of $\mathrm{Mg}-\mathrm{Zn}-\mathrm{Y}-\mathrm{Zr}$ alloys, which provided an obvious strengthening effect on the alloys, the ultimate tensile strength was improved to $342 \mathrm{MPa}$ when it was extruded at $400{ }^{\circ} \mathrm{C}$. In as-extruded Mg-Li- 
$\mathrm{Zn}-\mathrm{Gd}$ alloys, the dynamic recrystallization in Mg-8Li-3Zn$0.6 \mathrm{Y}$ alloy induced the generation of I-phase, which greatly improved the properties of alloys ${ }^{[12]}$.

Different from the thermoplastic forming process, the casting processes are widely used to produce complex castings with high quality, such as permanent mold casting, squeeze casting and rheo-squeeze casting ${ }^{[13]}$. Among them, the rheo-squeeze casting combines the advantages of traditional die casting and forging technology. During the rheo-squeeze casting, a semi-solid slurry is usually prepared by mechanical stirring, electromagnetic stirring or ultrasonic vibration processes, and then solidified and crystallized under pressure, so as to refine grains and gain a uniform alloy structure ${ }^{[14]}$. Among the above slurry-preparing processes, ultrasonic vibration has the characteristics of high efficiency, low cost and no pollution. It is widely acknowledged that the cavitation and acoustic streaming induced by ultrasonic vibration can remarkably refine primary grains. The intermetallic compound $\left(\delta-\mathrm{Al}_{4} \mathrm{FeSi}_{2}\right.$ phase) of hypereutectic Al-Si alloy with $2 \%$ Fe was refined effectively by the ultrasonic vibration, which was attributed to the effects of cavitation and acoustic streaming ${ }^{[15]}$. The eutectic Si of A356 alloy was refined when ultrasonic power was in a certain range, and coarsened with the further increase of ultrasonic power because of the affiliated heating effect ${ }^{[16]}$. Chen et al. ${ }^{[17]}$ found that the ultimate tensile strength (UTS), yield strength (YS) and elongation of 2024 wrought aluminum alloy using the ultrasonic vibration were $372 \mathrm{MPa}, 246 \mathrm{MPa}$ and $8.5 \%$, respectively, which were increased by $20.8 \%, 21.2 \%$ and $84.8 \%$, respectively, compared to the traditional squeeze casting sample. Based on the above investigations, it can be concluded that ultrasonic vibration is one of the simple and effective physical methods to refine alloy grain, and improves mechanical properties of alloys.

In this work, the effects of different casting processes (permanent mold casting, squeeze casting and rheo-squeeze casting with ultrasonic vibration) on microstructure evolution and mechanical properties of Mg-12Zn-2Y alloy were investigated. Meanwhile, the solidification precipitation behavior of quasicrystals I-phase in these three casting processes was discussed.

\section{Experimental procedure}

The Mg-12Zn-2Y magnesium alloy was prepared by commercial pure $\mathrm{Mg}$ (99.9\%, purity), pure Zn (99.9\%, purity) and Mg-30Y (wt.\%) master alloy. An ultrasonic vibration equipment (Scientz-J4T) for fabricating semisolid slurry was applied, which included a heating furnace, ultrasonic generator and ultrasonic vibrator. The maximum power of this equipment was $2,600 \mathrm{~W}$ and the frequency was maintained at $20 \mathrm{kHz}$. To prevent the rise of melt temperature caused by the thermal effect of ultrasonic vibration, the rest-work ratio $R_{\mathrm{t}}$ was set to 1, i.e., $R_{\mathrm{t}}=T_{\mathrm{r}} / T_{\mathrm{w}}, T_{\mathrm{r}}=1.0 \mathrm{~s}$ and $T_{\mathrm{w}}=1.0 \mathrm{~s}$. The JMatPro software was used to calculate the equilibrium phase diagram during solidification of Mg-12Zn-2Y alloy to determine the pouring temperature, and the results are shown in Fig. 1. The pouring temperature of the permanent mold casting and squeeze casting was $640{ }^{\circ} \mathrm{C}$, and for rheo-squeeze casting, the ultrasonic processing temperature was from $640{ }^{\circ} \mathrm{C}$ to $540{ }^{\circ} \mathrm{C}$.

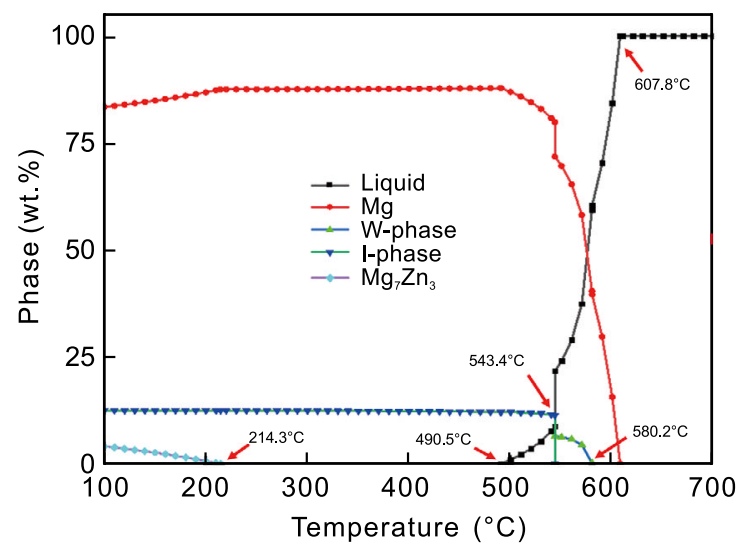

Fig. 1: Equilibrium phase diagram during solidification of Mg-12Zn-2Y alloy calculated by JMatPro software

Firstly, all the raw materials were put in a stainless-steel crucible with a well-type resistance furnace (SYDL SG2-512) for $30 \mathrm{~min}$ at $300{ }^{\circ} \mathrm{C}$ to remove water and oil. Then, in an atmosphere mixed with $1 \% \mathrm{SF}_{6}$ and $99 \% \mathrm{~N}_{2}$, the temperature was increased slowly to $750{ }^{\circ} \mathrm{C}$ until the raw materials were completely melted, in which the argon was pumped into the melt for refining. Table 1 shows the five groups of Mg-12Zn-2Y alloy samples fabricated by permanent mold casting (I) squeeze casting (II) and rheo-squeeze casting (III-V), respectively. When the temperature of the melt decreased to $640{ }^{\circ} \mathrm{C}$, the alloy of group I was poured into a metal mold preheated to $200{ }^{\circ} \mathrm{C}$. The alloy of group II was poured into squeeze casting mold preheated to $200{ }^{\circ} \mathrm{C}$ at $640{ }^{\circ} \mathrm{C}$, and was squeezed with the squeeze pressure of $50 \mathrm{MPa}$ immediately. For groups III, IV and $\mathrm{V}$, the $200 \mathrm{~mL}$ of melt was taken into a metal cup preheated to $600{ }^{\circ} \mathrm{C}$ (When the temperature difference between the melt temperature and the preheating temperature of the container is $20-50{ }^{\circ} \mathrm{C}$, the ultrasonic effect is better, so the preheating temperature of the container is set at $600{ }^{\circ} \mathrm{C}$ ). Then, the ultrasonic vibration head was inserted $10 \mathrm{~cm}$ below the surface of the melt. When the melt temperature decreased to $640{ }^{\circ} \mathrm{C}$, the ultrasonic generator would work for nearly $80 \mathrm{~s}$. During this process, the ultrasonic power was set to $800 \mathrm{~W}, 1,600 \mathrm{~W}$ and 2,400 W, respectively. Because the magnesium melt is easily oxidized, the atmosphere mixed $1 \% \mathrm{SF}_{6}$ and $99 \% \mathrm{~N}_{2}$ was inlet to metal cup as the protective gas during the vibration process. Following, the melt was poured into an extrusion mold preheated to $200{ }^{\circ} \mathrm{C}$, and was squeezed with the squeeze pressure of $50 \mathrm{MPa}$. After holding for $1 \mathrm{~min}$, a cylindrical ingot with $\Phi 35 \mathrm{~mm} \times 80 \mathrm{~mm}$ was obtained.

The specimens were cut from a position about $10 \mathrm{~mm}$ away from the bottom of the cylindrical ingots, then were grinded and polished and etched with 4 vol.\% nital. The microstructures were observed by an optical microscope (OM, Jiangnan MV4000) and scanning electron microscope (SEM, ZEISS $\Sigma$ IGMA 
300) equipped with an energy-dispersive X-ray spectrum analyzer (EDS). The specimens were thinned by ion milling, then characterized by a transmission electron microscope (TEM, FEI talos200x). The phase constitution of specimens was detected by the X-Ray diffractomer (XRD, PANalytical
X-Pert PRO MPD). The tensile properties were evaluated using a Shimadzu AG-IC vertical electronic universal testing machine at the strain rate of $1.0 \mathrm{~mm} \cdot \mathrm{min}^{-1}$, and the hardness tests were carried out on a Buchler digital Vickers hardness tester.

Table 1: Details of five groups of $M g-12 Z n-2 Y$ alloy samples

\begin{tabular}{ccccc} 
Samples & Casting processes & \multicolumn{3}{c}{ Parameters } \\
\cline { 3 - 4 } & Permanent mold casting & Ultrasonic power $(\mathbf{W})$ & Squeeze pressure $(\mathrm{MPa})$ & Pouring temperature $\left({ }^{\circ} \mathrm{C}\right)$ \\
II & Squeeze casting & - & - & 640 \\
III & Rheo-squeeze casting & 800 & 50 & 640 \\
IV & Rheo-squeeze casting & 1,600 & 50 & 537 \\
V & Rheo-squeeze casting & 2,400 & 50 & 538 \\
& & & 50 & 536
\end{tabular}

\section{Results and discussion}

\subsection{Permanent mold casting and squeeze casting}

Figures 2(a) and 2(b) show the SEM images of Mg-12Zn$2 \mathrm{Y}$ alloy specimens fabricated by permanent mold casting and squeeze casting. It can be noted that the microstructure of the permanent mold casting alloy consists of coarse $\alpha-\mathrm{Mg}$ and other phases with various morphologies (petaloid, grey and lamellar). In the sample by squeeze casting, the petaloid phase and grey phase disappear, and the content of $\alpha-\mathrm{Mg}$ and lamellar eutectics increases. Meanwhile the lamellar eutectics become more dispersive and the size of eutectic cells becomes smaller. As shown in the high magnification images [Figs. 2(c) and 2(d)], the eutectic lamellar spacing decreases in eutectic cells of the squeeze casting specimens. This spacing decrease is attributed to the higher cooling rate of squeeze casting over permanent mold casting.

The EDS analysis results of the permanent mold casting alloy [Points A, B, C, D in Fig. 2(c)] are shown in Table 2. The black part (Point $\mathrm{A}$ ) is $\alpha$-Mg matrix, in which a small amount of $\mathrm{Zn}$ is dissolved. In the petaloid phase (Point B), the ratio of $\mathrm{Zn} / \mathrm{Y}$ is about $6: 1$, corresponding to the $\mathrm{Zn} / \mathrm{Y}$ ratio of $\mathrm{I}-\mathrm{Mg}_{3} \mathrm{Zn}_{6} \mathrm{Y}$ phase. The $\mathrm{Mg} / \mathrm{Zn}$ ratio is close to $71.8: 28.2$ in
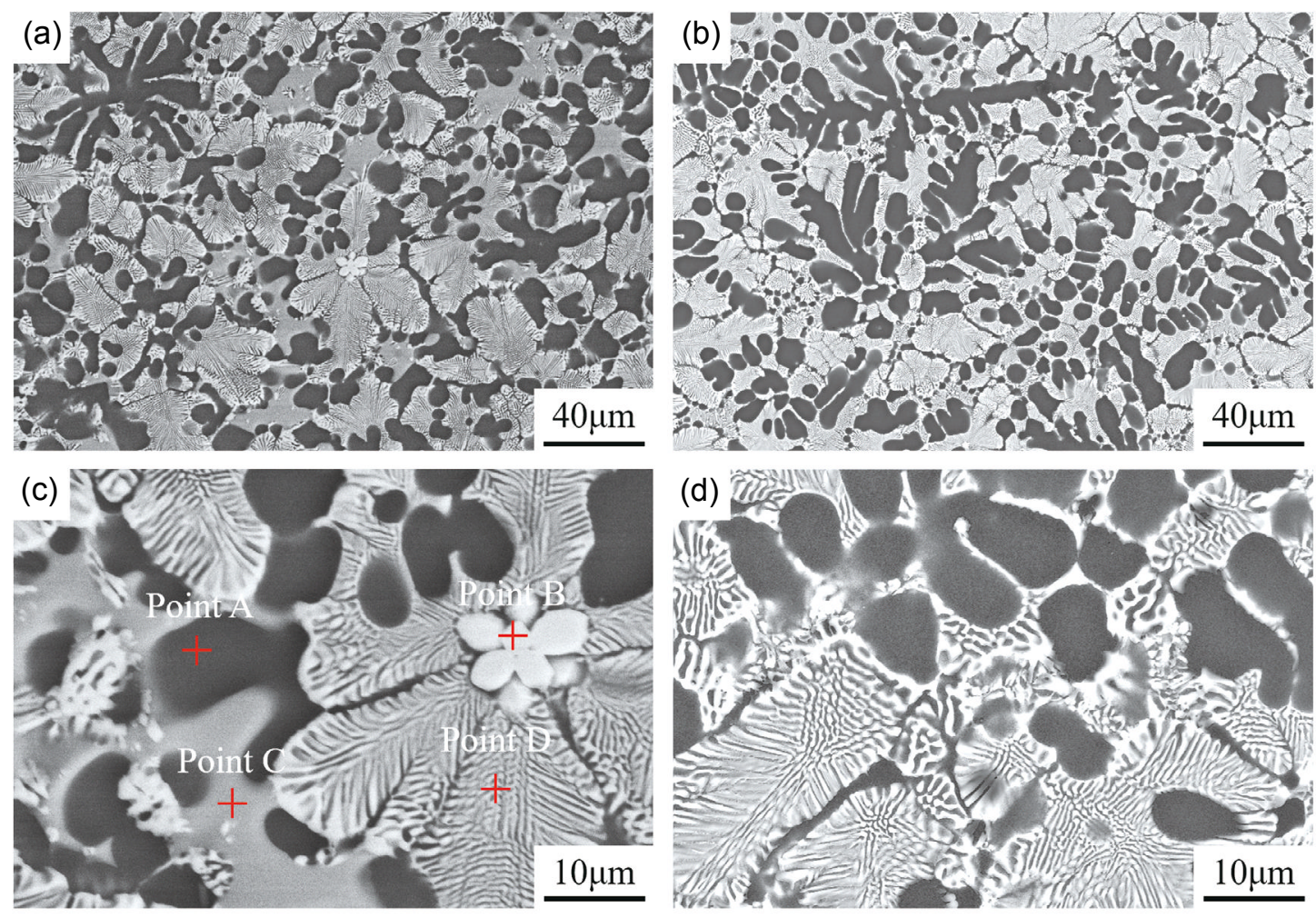

Fig. 2: SEM images of Mg-12Zn-2Y alloy fabricated by permanent mold casting (a, c) and squeeze casting (b, d) 
grey phase (Point C), which is presumed to be $\mathrm{Mg}_{7} \mathrm{Zn}_{3}$. The composition of lamellar eutectics (Point D) is Mg-26.5Zn3.7Y, which has been identified with the $\alpha-\mathrm{Mg}$ and I phase eutectic composition in another study ${ }^{[18]}$.

Table 2: EDS results of points in Fig. 2(c)

\begin{tabular}{cccc} 
& \multicolumn{2}{c}{ Element composition (at. \%) } \\
\hline Detected points & Mg & Zn & Y \\
\hline A & 96.55 & 3.45 & - \\
B & 43.90 & 48.03 & 8.07 \\
C & 71.80 & 28.20 & - \\
D & 69.78 & 26.48 & 3.74
\end{tabular}

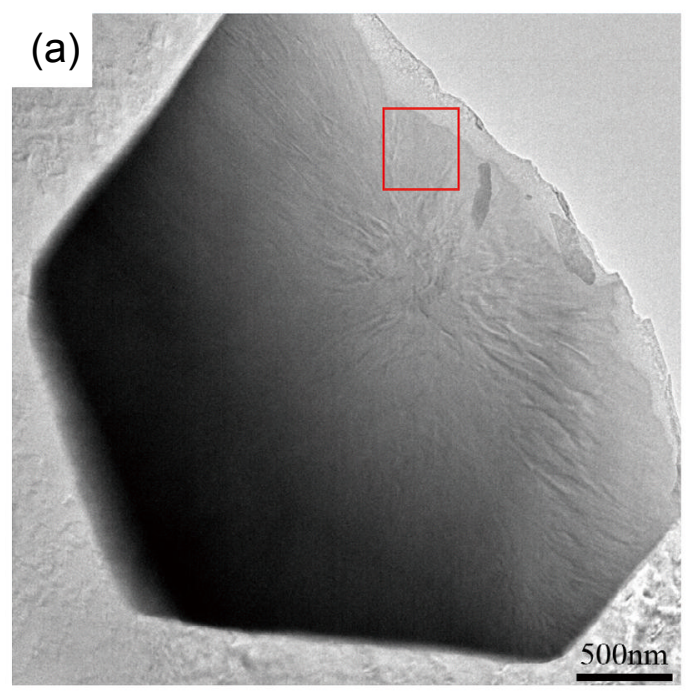

Fig. 3: Transmission electron microscope image of petaloid phase of $\mathrm{Mg}-12 \mathrm{Zn}-2 \mathrm{Y}$ alloy fabricated by permanent mold casting: (a) bright-field image of petaloid phase; (b) corresponding SAED pattern

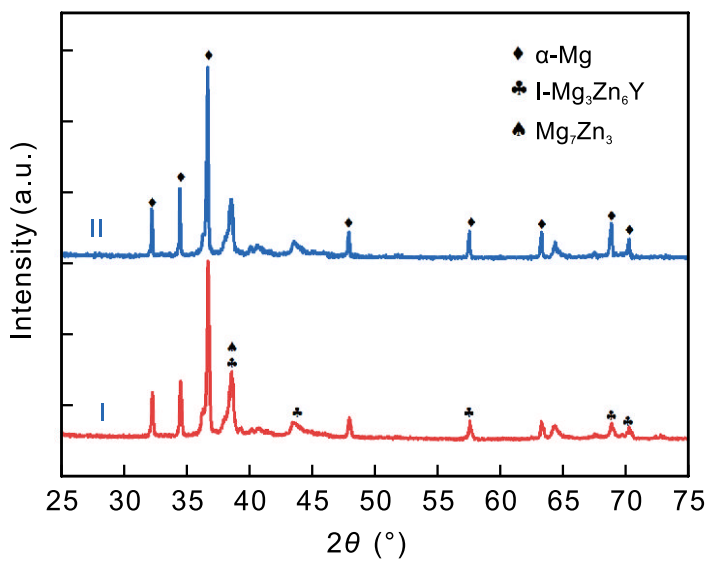

Fig. 4: X-Ray diffraction patterns of Mg-12Zn-2Y alloy fabricated by permanent mold casting (I) and squeeze casting (II)

\subsection{Rheo-squeeze casting}

Figure 5 is the SEM images of the microstructure for the alloys formed under squeeze pressure of $50 \mathrm{MPa}$ after different

\section{(b)}

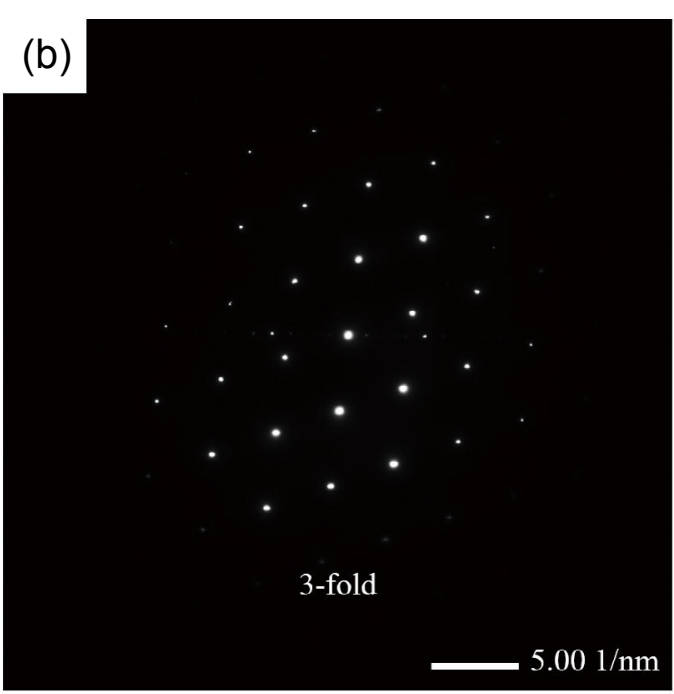

With regard to the petaloid phase, the composition is close to I-phase $\left(\mathrm{Mg}_{3} \mathrm{Zn}_{6} \mathrm{Y}\right)$. To further verify the petaloid phase, TEM image and diffraction analysis results are exhibited in Fig. 3. Figure 3(a) shows the diameter of petaloid phase is approximately $3.500 \mu \mathrm{m}$. Figure 3(b) displays the SAED pattern of the petaloid phase. It shows a typical selected area electron diffraction pattern at threefold symmetry, which verifies that the petaloid phase is an icosahedral quasicrystal structure.

The XRD patterns of the permanent mold casting and squeeze casting specimens are shown in Fig. 4, verifying that the gray phase is $\mathrm{Mg}_{7} \mathrm{Zn}_{3}$, and demonstrating that $\mathrm{Mg}-12 \mathrm{Zn}$ $2 \mathrm{Y}$ alloy is mainly composed of $\alpha-\mathrm{Mg}, \mathrm{Mg}_{7} \mathrm{Zn}_{3}$ and I-phase. Meanwhile, the characteristic peaks of $\mathrm{Mg}_{7} \mathrm{Zn}_{3}$ phase decrease in squeeze casting, and the intensity of $\alpha-\mathrm{Mg}$ and quasicrystal phase (I-phase) peaks increase, which accords with the results of the SEM microstructure images. 

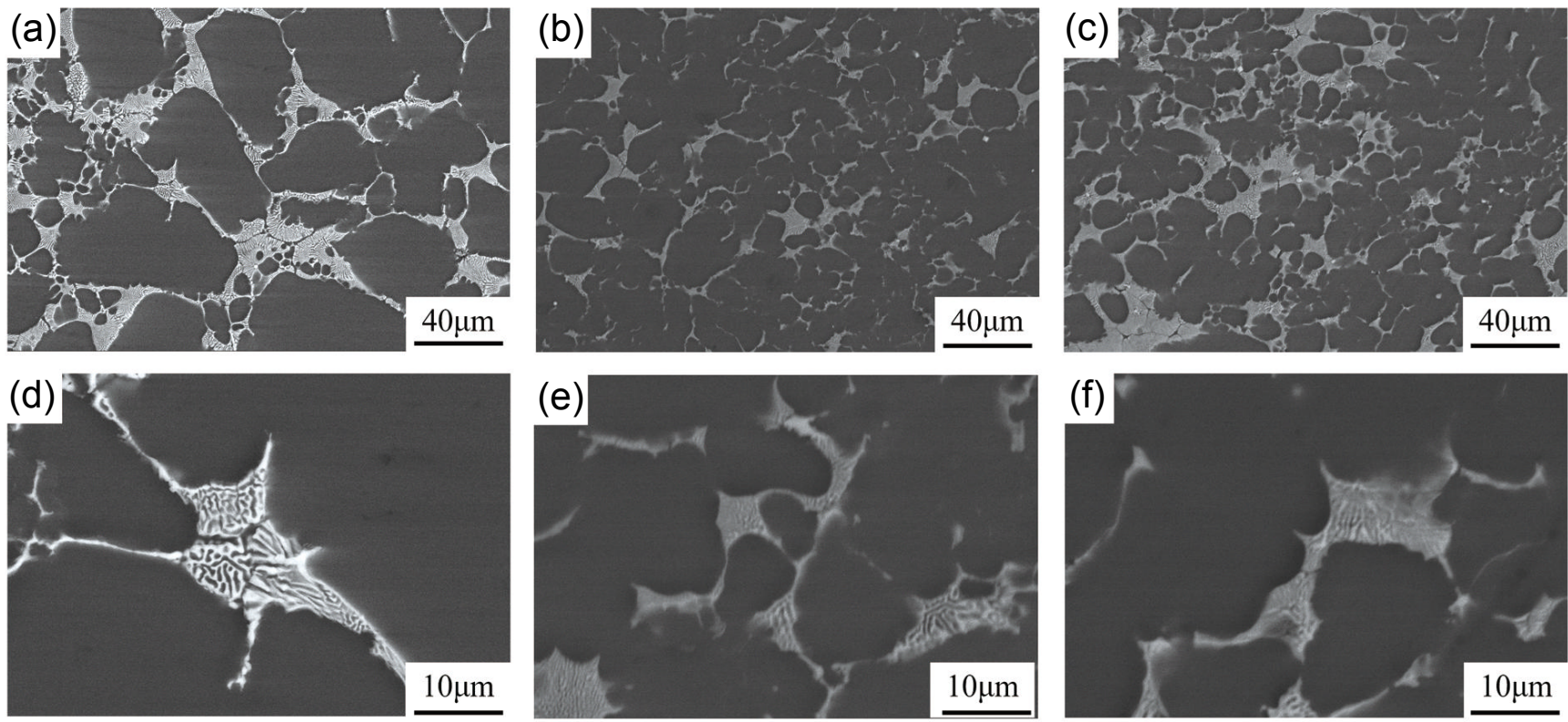

Fig. 5: SEM images of rheo-squeeze casting Mg-12Zn-2Y alloy with different ultrasonic powers: (a, d) $800 \mathrm{~W}$; (b, e) $1,600 \mathrm{~W}$; (c, f) $2,400 \mathrm{~W}$
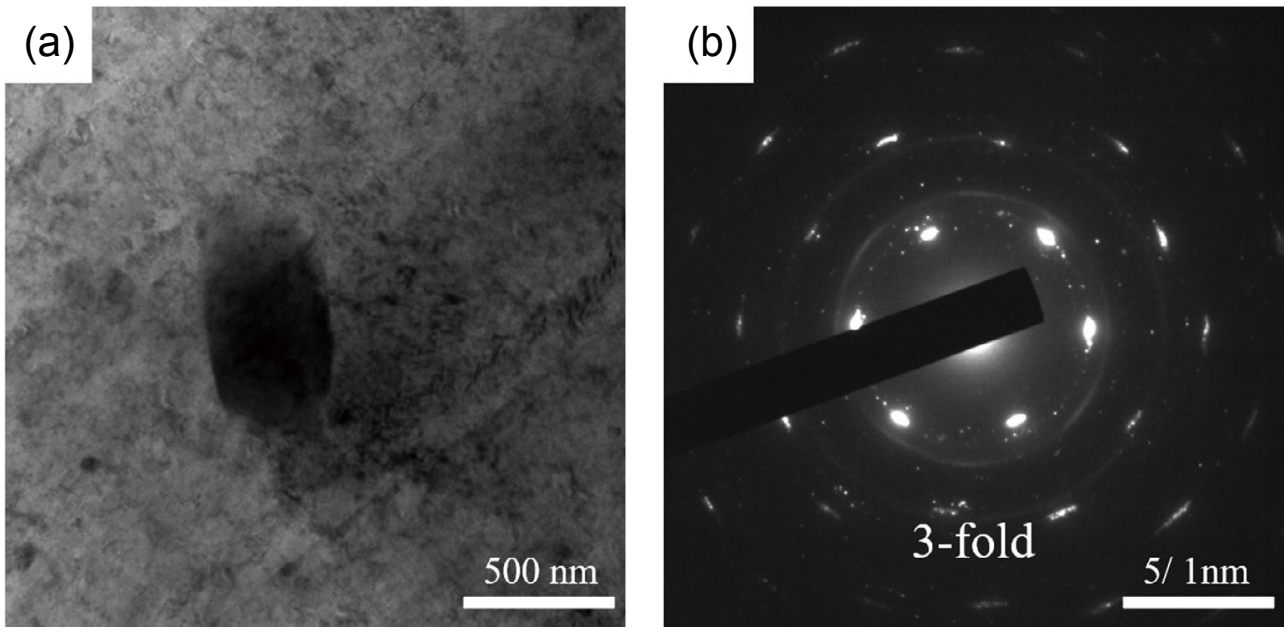

Fig. 6: TEM images of tiny particle in Mg-12Zn-2Y alloy treated by ultrasonic vibration with a power of 1,600 W: (a) bright-field TEM image; (b) SAED pattern

alternating ultrasonic field. During the stage of negative pressure, a large number of cavitation bubbles form and absorb a lot of heat, leading to the high undercooling in the area around the bubbles, which benefits the formation of crystal nucleus ${ }^{[20]}$. Gao et al. ${ }^{[21]}$ found that the number of bubbles increased gradually with the intensified ultrasonic power. Furthermore, under compressive stress, the cavitation bubbles burst acutely and generate a high pressure, which effectively decreases the solidifying point of melt and results in the formation of numerous crystal nucleus ${ }^{[22,23]}$. In addition, the growing dendritic arms are broken by the high pressure, which become another source of nuclei ${ }^{[24]}$. During the introduction of ultrasonic vibration, a certain gradient of amplitude attenuation is generated in the whole melt, which leads to an acoustic flow from the source in the direction of attenuation. Under the acoustic flow, the melt has a violent stirring and vibration effect, and the temperature of solid and liquid phases is more evenly distributed in the melt. Therefore, the growth rate of grains in all directions is similar, which promotes the near-spherical growth of grains. Meanwhile, the acoustic streaming alleviates the enrichment of $\mathrm{Zn}$ and $\mathrm{Y}$ along the grain boundaries. In addition, since the average size of primary $\alpha-\mathrm{Mg}$ is reduced, the number of $\alpha-\mathrm{Mg}$ grains in the identical sectional area is increased, which contributes to the refinement of the compounds along the grain boundaries. Hence, it can be concluded that ultrasonic vibration is beneficial to the dispersive distribution of the secondary phase. However, when the ultrasonic power is increased to $2,400 \mathrm{~W}$, part of the mechanical energy generated by ultrasonic vibration is converted into heat energy, and the undercooling degree of the melt is decreased, thus weakening the refinement of $\alpha-\mathrm{Mg}$ grains, which is adverse to the dispersive distribution of the secondary phases. Hence, the appropriate ultrasonic power can promote the formation of crystal nucleus, leading to grain refinement.

The XRD patterns of Mg-12Zn-2Y alloy fabricated by rheo- 
squeeze casting with different ultrasonic powers are shown in Fig. 7. The results show that the change of ultrasonic power has no conspicuous impact on the phase constitutions. All the alloys are mainly composed of $\alpha-\mathrm{Mg}, \mathrm{I}-\mathrm{Mg}_{3} \mathrm{Zn}_{6} \mathrm{Y}$ phase, and a small quantity of $\mathrm{Mg}_{7} \mathrm{Zn}_{3}$. In addition, the magnified diffraction peak corresponding to $\alpha-\mathrm{Mg}$ shifts to the right, which indicates the lattice constant of $\alpha-\mathrm{Mg}$ phase is decreased with the increase of ultrasonic power. It can be deduced that the change of lattice constant is caused by the increase of solid solubility of $\mathrm{Zn}$ element in the matrix ${ }^{[25]}$.

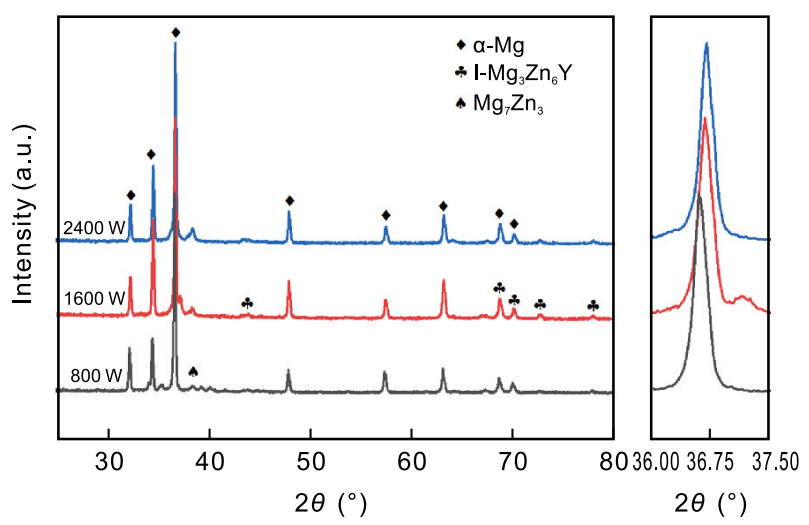

Fig. 7: XRD patterns of Mg-12Zn-2Y alloy fabricated by rheo-squeeze casting with different ultrasonic powers

\subsection{Mechanical properties and fracture analysis}

The microhardness of Mg-12Zn-2Y alloys treated by permanent mold casting, squeeze casting and rheo-squeeze casting under different ultrasonic powers is shown in Fig. 8. Compared with permanent mold casting, the microhardness of the squeeze casting alloy is increased by $11.6 \%$, reaching $56.6 \mathrm{HV}$. With the increase of ultrasonic power, the microhardness of the alloys increases to a maximum of $79.9 \mathrm{HV}$ at $1,600 \mathrm{~W}$, which is $41 \%$ higher than the $56.6 \mathrm{HV}$ of the sample with squeeze casting. However, when the ultrasonic power is further increased to $2,400 \mathrm{~W}$, the microhardness of the alloy decreases, but it is still higher than that of $800 \mathrm{~W}$. It can be seen that

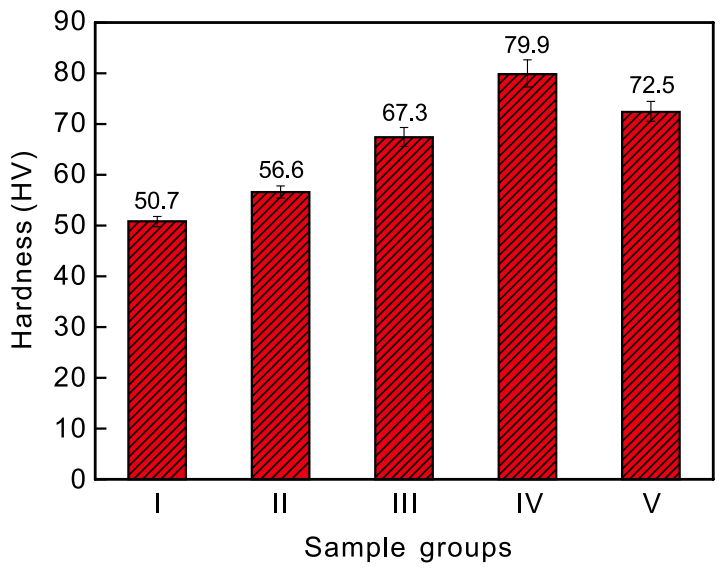

Fig. 8: Microhardness of alloys treated by different casting processes shown in Table 1 within a certain range of ultrasonic power, the introduction of ultrasonic vibration improves the microhardness of the alloy. However, when the ultrasonic power increases to $2,400 \mathrm{~W}$, excessive mechanical energy is converted into heat energy, which leads to the decrease in cooling rate of subsequent squeeze casting. In this case, the uniform distribution of eutectic structure at the grain boundary is deteriorated [as shown in Fig. 5(c)], thus leading to the decrease of alloy hardness.

Figure 9 shows the tensile properties of $\mathrm{Mg}-12 \mathrm{Zn}-2 \mathrm{Y}$ alloys fabricated by different casting processes at room temperature. The yield strength, ultimate tensile strength and elongation of the squeeze casting samples are $111 \mathrm{MPa}, 188 \mathrm{MPa}$ and $1.41 \%$, respectively. Compared with the permanent mold casting sample, the yield strength, ultimate tensile strength and elongation are improved by $14.4 \%, 35.3 \%$ and $52.2 \%$, respectively. In specimens fabricated by rheo-squeeze casting, when the ultrasonic powers are $800 \mathrm{~W}$ and $1,600 \mathrm{~W}$, the tensile properties improve obviously. And when the ultrasonic power is $1,600 \mathrm{~W}$, the yield strength, ultimate tensile strength and elongation values are $140 \mathrm{MPa}, 236 \mathrm{MPa}$ and 3.25\%, which are increased by $26.1 \%, 25.5 \%$ and $132.1 \%$, respectively, compared with the samples of squeeze casting. However, when the ultrasonic power increases to $2,400 \mathrm{~W}$, the yield strength, ultimate tensile strength and elongation decline slightly. Therefore, it can be inferred that the optimal ultrasonic power is $1,600 \mathrm{~W}$ for rheo-squeeze casting $\mathrm{Mg}-12 \mathrm{Zn}-2 \mathrm{Y}$ alloy.

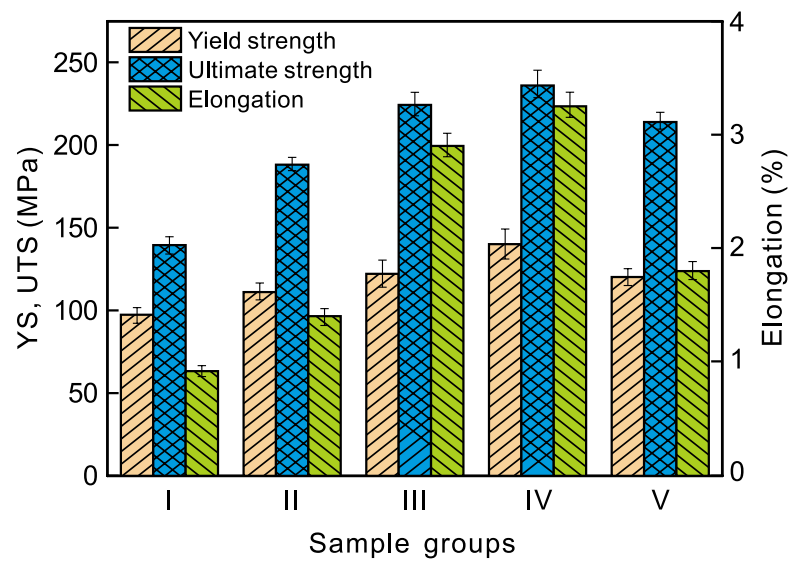

Fig. 9: Tensile properties of Mg-12Zn-2Y alloy fabricated by different processes

To research the fracture mechanism, the fracture surfaces SEM images of the squeeze casting and rheo-squeeze casting Mg-12Zn-2Y alloy are shown in Fig. 10. Without ultrasonic vibration, the whole fracture surface is dominated by bulky cleavage planes, which indicates the characteristic of cleavage fracture. With the ultrasonic vibration power increases to $1,600 \mathrm{~W}$, an increasing number of cleavage steps are gradually replaced by small-sized dimples. However, the number of small dimples decreases significantly with the power increases to $2,400 \mathrm{~W}$. Therefore, the fracture type of rheo-squeeze casting $\mathrm{Mg}-12 \mathrm{Zn}-2 \mathrm{Y}$ alloy is a mixture of cleavage fracture and ductile fracture. 

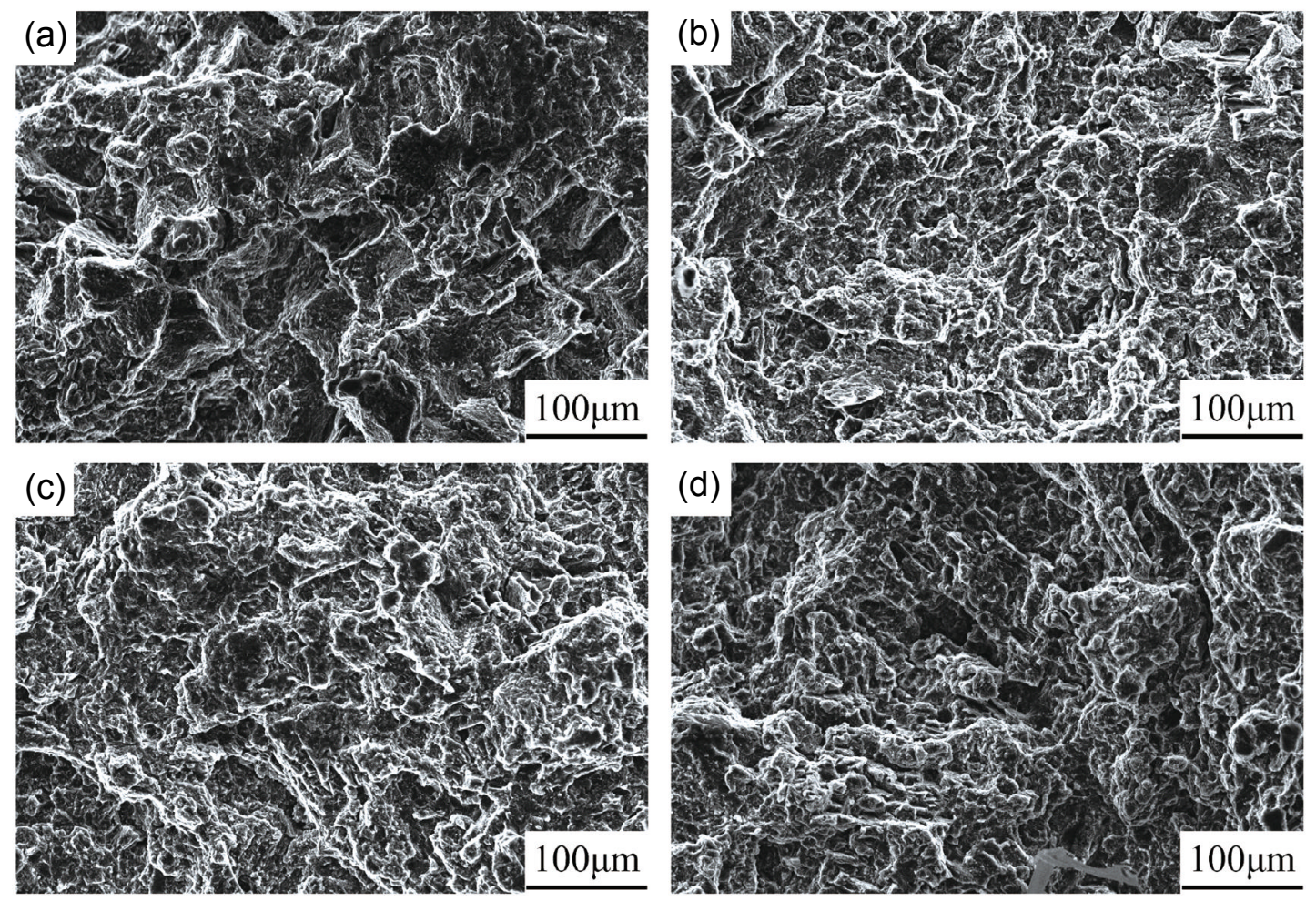

Fig. 10: SEM images of microstructure of tensile fractures for Mg-12Zn-2Y alloy fabricated by squeeze casting (a) and rheo-squeeze casting with different ultrasonic powers: (b) $800 \mathrm{~W}$; (c) 1,600 W; (d) 2,400 W

Similar to the other investigations, the adoption of the rheo-squeeze casting process contributes to the simultaneous improvements in the tensile strength and elongation ${ }^{[2,27]}$. There are three main reasons that account for the improvements. Firstly, the samples fabricated by squeeze casting and rheosqueeze casting have higher compactness than permanent casting, which results in simultaneous improvement in strength and elongation ${ }^{[14]}$. Secondly, as depicted above, the introduction of ultrasonic vibration leads to the reduction in the size of $\alpha-M g$ grains, and the refinement of microstructure is widely confirmed as an effective way to improve the strength and elongation at the same time ${ }^{[26]}$. Thirdly, the morphology, size, and distribution of intermetallic compounds, especially the quasicrystal I-phase, also play a significant role in the mechanical performances. For the permanent cast $\mathrm{Mg}-12 \mathrm{Zn}$ $2 \mathrm{Y}$ alloy, the concentration of massive coarse icosahedral Mg$\mathrm{Zn}-\mathrm{Y}$ phases leads to stress concentration, offering sources of micro-cracks and causing the decline in the ductility ${ }^{[13]}$. As to the rheo-squeeze casting sample, the coarse icosahedral quasicrystal disappears and lamellar eutectic structure is refined markedly. Meanwhile, some of the I-phase transform to tiny and dispersive particles in the matrix. The interface layer between $\alpha-\mathrm{Mg}$ and I-phase particles maintains the coherency relationship because of the periodical steps and ledges along the interface ${ }^{[7]}$. In addition, there is rigid atomic bonding between I-phase particles and hexagonal structure, which can effectively hinder the movement of dislocation, thus contributing to the improvement of tensile properties ${ }^{[18]}$. Therefore, the elongation of Mg-12Zn-2Y alloy increases remarkably.

\section{Conclusions}

The microstructure and mechanical properties of Mg-12Zn-2Y alloy fabricated by permanent mold casting, squeeze casting and rheo-squeeze casting were systematically investigated and compared. The main results can be summarized as follows:

(1) The microstructure of the permanent mold cast sample consists of coarse $\alpha-\mathrm{Mg}, \mathrm{Mg}_{7} \mathrm{Zn}_{3}$, petaloid icosahedral quasicrystal phase (I-phase) and lamellar eutectics $(\alpha-\mathrm{Mg}$ and I-phase). For squeeze-cast alloy, the petaloid I-phase disappears and the amount of $\mathrm{Mg}_{7} \mathrm{Zn}_{3}$ phase reduces.

(2) In rheo-squeeze casting microstructure, the $\alpha-\mathrm{Mg}$ changes from large dendritic crystal to nearly spherical grains. With the increase of ultrasonic power from $800 \mathrm{~W}$ to $1,600 \mathrm{~W}$, the size of $\alpha-\mathrm{Mg}$ grain decreases gradually, and the lamellar eutectics distribute more uniformly along the boundaries of grain. Meanwhile, the spacing of lamellar eutectic diminishes, and some tiny quasicrystal I-phase particles appear in the $\alpha-M g$ matrix. However, when the ultrasonic power increases persistently to $2,400 \mathrm{~W}$, the uniform distribution of eutectic structure at grain boundary is deteriorated.

(3) The microhardness, yield strength, ultimate tensile strength and elongation of squeeze casing alloy are $56.6 \mathrm{HV}$, $111 \mathrm{MPa}, 188 \mathrm{MPa}$ and $1.41 \%$, which are $11.6 \%, 14.4 \%$, $35.5 \%$ and $52.2 \%$ higher than the corresponding properties of permanent mold cast alloy. For rheo-squeeze casting alloy, when the ultrasonic power is $1,600 \mathrm{~W}$, the microhardness, yield strength, ultimate tensile strength and elongation are the best, reaching $79.9 \mathrm{HV}, 140 \mathrm{MPa}, 236 \mathrm{MPa}$ and $3.25 \%$, respectively. 


\section{Acknowledgements}

This study was financially supported by the Natural Science Foundation of Anhui Province (No. 1908085QE197), the State Key Laboratory of Materials Processing and Die \& Mould Technology, Huazhong University of Science and Technology (P2019-024) and the Fundamental Research Funds for the Central Universities (JZ2019HGTA0043).

\section{References}

[1] Yamasaki M, Hashimoto K, Hagihara K, et al. Effect of multimodal microstructure evolution on mechanical properties of Mg-Zn-Y extruded alloy. Acta Materialia, 2011, 59(9): $3646-3658$.

[2] Wang S D, Xu D K, Chen X B, et al. Effect of heat treatment on the corrosion resistance and mechanical properties of an asforged Mg-Zn-Y-Zr alloy. Corrosion Science, 2015, 92: 228-236.

[3] Zhan L, Le $Y Z$, Feng $Z$ J, et al. Effect of Gd addition on mechanical and microstructural properties of $\mathrm{Mg}-x \mathrm{Gd}-2.6 \mathrm{Nd}-$ $0.5 Z n-0.5 Z r$ cast alloys. China Foundry, 2020, 17(3): 212-218.

[4] Shao X H, Yang Z Q, Ma X L. Strengthening and toughening mechanisms in $\mathrm{Mg}-\mathrm{Zn}-\mathrm{Y}$ alloy with a long period stacking ordered structure. Acta Materialia, 2010, 58(14): 4760-4771.

[5] Wan D Q, Wang H B, Li Z M, et al. Aging kinetics of 14H-LPSO precipitates in Mg-Zn-Y alloy. China Foundry, 2020, 17(1): $42-47$.

[6] Luo Z P, Zhang S Q, Tang Y L, et al. Quasicrystals in as-cast Mg-Zn-RE alloys. Scripta Metallurgica et Materiala, 1993, 28(12): 1513-1518.

[7] Chen X R, Ning S C, Wang A, et al. Microstructure, mechanical properties and corrosion behavior of quasicrystal-reinforced $\mathrm{Mg}-\mathrm{Zn}-\mathrm{Y}$ alloy subjected to dual-frequency ultrasonic field. Corrosion Science, 2020, 163: 108289.

[8] Yu H Y, Yan H G, Chen J H, et al. Effects of minor Gd addition on microstructures and mechanical properties of the high strain-rate rolled $\mathrm{Mg}-\mathrm{Zn}-\mathrm{Zr}$ alloys. Journal of Alloys and Compounds, 2014, 586: 757-765.

[9] Huang $\mathrm{H}$, Chen $\mathrm{C} L$, Wang $Z \mathrm{C}$, et al. Effect of pretreatment and annealing on microstructure and mechanical properties of $\mathrm{Mg}-1.5 \mathrm{Zn}-0.25 \mathrm{Gd}$ (at\%) alloys reinforced with quasicrystal. Materials Science and Engineering: A, 2013, 581: 73-82.

[10] Singh A, Osawa Y, Somekawa $\mathrm{H}$, et al. Effect of microstructure on strength and ductility of high strength quasicrystal phase dispersed $\mathrm{Mg}-\mathrm{Zn}-\mathrm{Y}$ alloys. Materials Science and Engineering: A, 2014, 611: 242-251.

[11] Zhang $Y$, Zeng $X Q$, Liu L F, et al. Effects of yttrium on microstructure and mechanical properties of hot-extruded Mg$\mathrm{Zn}-\mathrm{Y}-\mathrm{Zr}$ alloys. Materials Science and Engineering: A, 2004, 373(1-2): 320-327.
[12] Zhang $\mathrm{Y}$, Zhang J, Wu G H, et al. Microstructure and tensile properties of as-extruded Mg-Li-Zn-Gd alloys reinforced with icosahedral quasicrystal phase. Materials and Design, 2015, 66: $162-168$

[13] Srivastava N, Anas M. An investigative review of squeeze casting: Processing effects \& impact on properties. Materials Today: Proceedings, 2019, 26: 1914-1920.

[14] Lü S L, Wu S S, Lin C, et al. Preparation and rheo-casting of semisolid slurry of $5083 \mathrm{Al}$ alloy with indirect ultrasonic vibration process. Materials Science and Engineering: A, 2011, 528(29-30): 8635-8640.

[15] Lin C, Wu S S, Lü S L, et al. Microstructure and mechanical properties of rheo-diecast hypereutectic Al-Si alloy with $2 \% \mathrm{Fe}$ assisted with ultrasonic vibration process. Journal of Alloys and Compounds, 2013, 568: 42-48.

[16] Jian X, Meek T T, Han Q. Refinement of eutectic silicon phase of aluminum A356 alloy using high-intensity ultrasonic vibration. Scripta Materialia, 2006, 54(5): 893-896.

[17] Chen G, Yang M, Jin Y, et al. Ultrasonic assisted squeeze casting of a wrought aluminum alloy. Journal of Materials Processing Technology, 2019, 266: 19-25.

[18] Xu D K, Han E H. Effects of icosahedral phase formation on the microstructure and mechanical improvement of Mg alloys: A review. Progress in Natural Science: Materials International, 2012, 22(5): 364-385.

[19] Tong $X$, You $G Q$, Wang $Y$ C, et al. Effect of ultrasonic treatment on segregation and mechanical properties of as-cast Mg-Gd binary alloys. Materials Science and Engineering: A, 2018, 731: 44-53.

[20] Eskin G I. Broad prospects for commercial application of the ultrasonic (cavitation) melt treatment of light alloys. Ultrasonics Sonochemistry, 2001, 8(3): 319-325.

[21] Gao D M, Li Z J, Han Q Y, et al. Effect of ultrasonic power on microstructure and mechanical properties of AZ91 alloy. Materials Science and Engineering A, 2009, 502(1-2): 2-5.

[22] Fang $X$ G, Lü $S S$, Zhao $L$, et al. Microstructure and mechanical properties of a novel Mg-RE-Zn-alloy fabricated by rheosqueeze casting. Materials and Design, 2016, 94: 353-359.

[23] Ma R, Dong X P, Yan B S, et al. Mechanical and damping properties of thermal treated $\mathrm{Mg}-\mathrm{Zn}-\mathrm{Y}-\mathrm{Zr}$ alloys reinforced with quasicrystal phase. Materials Science and Engineering: A, 2014, 602: 11-18.

[24] Xu D K, Tang W N, Liu L, et al. Effect of W-phase on the mechanical properties of as-cast Mg-Zn-Y-Zr alloys. Journal of Alloys and Compounds, 2008, 461(1-2): 248-252.

[25] Jiang W, Zou C M, Chen Y, et al. The effect of pressureinduced Mg64Zn15Y21 phase on the mechanical properties of $\mathrm{Mg}-\mathrm{Zn}-\mathrm{Y}$ alloy. Journal of Alloys and Compounds, 2020, 840: 155682.

[26] Han S Z, Choi E, Lim S H, et al. Alloy design strategies to increase strength and its trade-offs together. Progress in Materials Science, 2020, 100720. 